\title{
The Transcendental Method and Physical Cosmology: an Interdisciplinary Approach in the Research of Ukrainian and Anglo-American Philosophers
}

\author{
Sergii Rudenko \\ Doctor of Philosophical Sciences, Professor, Guangdong University of Petrochemical \\ Technology (Maoming, Guangdong Province, China), Taras Shevchenko National \\ University of Kyiv (Kyiv, Ukraine) \\ E-mail: rudenkosrg@gmail.com \\ https://orcid.org/0000-0001-9069-0989
}

\section{Yaroslav Sobolievskyi}

Ph.D., Associate Professor, Taras Shevchenko National University of Kyiv (Kyiv, Ukraine)

E-mail: yasobolevsky@gmail.com

https://orcid.org/0000-0001-8251-2744

\begin{abstract}
In modern science, an important feature is a fact that interdisciplinary research is becoming more popular. This is due to the mutual interest of different areas of science to the methods and principles of other areas. The article is devoted to the study of the possibility of dialogue between physical cosmology and transcendental philosophy. Transcendental philosophy provides an interesting look at the problem of subject-object relations in which the object depends on the observer. The possibility of science using a specific transcendental method in the field of astrophysics has been studied. This possibility is due to the specifics of astronomical objects that exist for the observer as phenomena that do not correspond to reality in time and space. The article emphasizes the conventional concept of realism in modern science. The interdisciplinary dialogue of American and Ukrainian philosophical cosmology with its methods and physical cosmology with its objects promotes mutual development.
\end{abstract}

Keywords: the history of philosophy, transcendental method, physical cosmology, philosophical cosmology.

Received: April 6, 2019; accepted: May 24, 2019

Philosophy and Cosmology, Volume 23, 2019: 157-167.

https://doi.org/10.29202/phil-cosm/23/15

(C) Rudenko, Sergii, 2019

(C) Sobolievskyi, Yaroslav, 2019 


\section{Introduction}

Transcendental philosophy changes the object of study, it is not the thing (as it is in naturalism), but the analysis of the conditions for the possibility of their cognition. In the Critique of Pure Reason, 1781, German philosopher Immanuel Kant (1724-1804) defines a new methodological strategy, what he called the changed method in our way of thinking. This means that philosophy does not examine the object, but the transcendental conditions that make it an object of knowledge. In this way, Immanuel Kant accomplishes the "Copernican revolution" in metaphysics from substance to a subject, who perceives objects. The transcendental turn in philosophy passed in three directions: firstly, transcendental idealism, secondly, neo-Kantianism and transcendental phenomenology, which became popular in Europe analytical Kantianism, and thirdly, analytic philosophy. All these three areas are different from one another, but on the other hand, complement each other. There are different classifications, but for research, it is important to use the essence of the transcendental method and transcendental philosophy. The purpose of this article is to answer the question about, what does transcendental turn in philosophy mean for philosophical cosmology?

\section{An object of study in transcendental philosophy}

When we try to answer the question of what a transcendental turn in philosophy is, we find that on the one hand, it is a new metaphysics with its ideas, on the other - the theory of experience, or modern philosophy of science, on the third - the theory of consciousness. In turn, the transcendental turn shifted the emphasis of philosophy from a substance, from the doctrinal conviction in the existence of the external world and its objects to the internal world, the subjective world. Thus, man no longer existed in space, but the cosmos was constructed in the consciousness of man. Transcendental (from the Latin Transcendens - on the other side) literally means going beyond. In the $20^{\text {th }}$ century, Immanuel Kant and his philosophy were rediscovered, primarily within the framework of analytical philosophy. It is associated with the names of Peter Strawson, Wilfrid Sellars, John Bennett, and many others. Transcendental philosophy of Immanuel Kant made a turn in the understanding of man and his being, and the doctrine of being, or metaphysics, was the main philosophical discipline in antiquity and in the Middle Ages. In the history of philosophy, human existence was understood secondary, it was not the main problem, and the best fate of man was presented as contemplation and obedience to higher Being. The transcendental turn in philosophy changed the perception of a person who turned out to be the center of a coordinate system. The human "Ego" was not recognized as a fundamental entity, but its creative activity, which constitutes the phenomenal world, came to the fore. After transcendental turn "Ego" has become the only source of activity that generates things. The French philosopher Rene Descartes (1596-1650) believed that not the divine, but the human "Ego" is the most obvious reality, and it is in itself regarded as a constant source of mental activity, creating the world inside human consciousness. The things of the external world, as a phenomenon of consciousness, according to Immanuel Kant, represent the unity of the content and the act of its design. A new approach to Immanuel Kant's transcendentalism was proposed by Edmund Husserl (1859-1938). He focused on passive contemplation, and not just the constructive activity of the "Ego", however, in the transcendental philosophy, the ontological status of things remains unclear. The Lifeworld appears in the phenomenology of Edmund Husserl not only as of the ground of science. Our everyday experience has the ability to provide access to "the things themselves", to the real world. Perception, despite its non-verbal character, Edmund Husserl also refers to the 
cognitive act. In this case, it implies clarifying the conditions for the possibility that in the everyday experience we are given a "real" world. According to Edmund Husserl knowledge of essences can be possible by bracketing all assumptions about the existence of an external world [Husserl, 1982].

However, the new methodological strategy, which Immanuel Kant calls the changed method of thinking, according to which if we ask about the possibility of knowing a priori, we proceed not from the object, but from the transcendental conditions that make it an object of possible knowledge. Visible space and perceived time according to the transcendental philosophy are the conditions of perception. In transcendental philosophy, the experience is the beginning of knowledge, according to Immanuel Kant, the connection of the elements of experience refers to the necessary a priori activity of the mind. This activity of the mind with experience Immanuel Kant considers transcendental research: "I call all cognition transcendental that is occupied not so much with objects but rather with our mode of cognition of objects insofar as this is to be possible a priori. A system of such concepts would be called transcendental philosophy." [Kant, 1998: 149]. The history of transcendental philosophy can be divided into several stages. The first stage is the transcendental philosophy, already mentioned, by Immanuel Kant. This stage influenced the emergence of German transcendental idealism. The transcendental methodology originally existed in philosophy, but over time it began to move into science, or rather, this methodology tried to be more scientific. It refers to the term "science" as it was understood in the $19^{\text {th }}$ century. On the next stages, neo-Kantianism and transcendental phenomenology brought an idea to make philosophy a strict science. The next stage in the history of philosophical thought was the "linguistic turn", characterized by transcendental logic. On the one hand, this stage is associated with positivism and analytical philosophy, and on the other hand, this period is associated with epistemological constructivism. Despite the conceptual differences between the historical phases of the development of transcendental philosophy, common to them is the transcendental methodology. Transcendental philosophy studies the cognitive abilities rather than the empirical elements of our knowledge; it studies the transcendental conditions of cognitive activity, including scientific knowledge.

Using the achievements of transcendental philosophy, especially its methodology and terms, natural sciences, it is possible to increase the general scientific methodology. In his early works, Immanuel Kant explored space and its evolution. This fact suggests an opportunity to make an attempt to combine cosmological knowledge with transcendental methodology.

Transcendental philosophy or transcendentalism, both terms are used as synonyms. First, transcendentalism is a form of theory of knowledge; secondly, transcendentalism is a characteristic of the views of a number of philosophers, as mentioned - Immanuel Kant or Edmund Husserl; and thirdly, transcendentalism in a broad sense is a historical and philosophical trend, the focus of which is on the concepts of transcendental and transcendent. The task of transcendental philosophy is to clarify the conditions and boundaries of human cognition, the objectivity, and intersubjectivity of knowledge associated with ontology.

In the relationship between experience and intellect Immanuel Kant reconciles two traditions, knowledge is impossible without the interaction of sensory experience and intellect. Any experimental science begins with sensory knowledge with a further erection into abstract concepts, a priori forms of sense that transform the flow of sensory data into phenomena. Thus, visual space is an experience of space that is created by an observer. Visual space is a subjective analog of the space of physical objects. "Subordination of phenomena to 
categories, and, consequently, reasoning occurs on the following grounds: 1) all phenomena are in space and time; 2) the a priori synthesis of representation a priori concerns the space itself and time; 3 ) phenomena must obey the transcendental unity of such synthesis, as well as the categories that represent this unity a priori." [Minakov, 2006: 40].

In the Anglo-American philosophical tradition, transcendental philosophy is usually associated with the name of the founder of the transcendentalism movement, Ralph Waldo Emerson (1803-1882). In his interpretation, the idealistic philosophy of German transcendentalism received a peculiar interpretation. For Ralph Emerson, transcendentalism was idealism, closer to romanticism in art than to science in its modern sense: If the stars should appear one night in a thousand years, how would men believe and adore; and preserve for many generations the remembrance of the city of God which had been shown! But every night come out these preachers of beauty, and light the universe with their admonishing smile." [Emerson, 1836: 9-10]. For a philosopher, the whole world of earthly and celestial objects consisted not of matter, in its scholastic understanding, but of the ideas of human consciousness. The whole world is built in such a way that it is very convenient for humanity. All the laws of physics and logic, all the constants and maxima exist not just like that, but especially for life. In modern philosophy of cosmology, this theory is studied as an Anthropic Principle.

\section{Transcendental cosmos in philosophical cosmology and realism}

In philosophical cosmology there are questions about the limits of scientific knowledge, the fact is that in cosmology there are no features present in other areas of physics. Physical laws describe the functions of an immutable system; explanations of these laws often work if they are inductively applied to a wider context. But this does not happen, for example, with the theory of the initial state, it cannot appeal to any of the ideas. Scientists have access to study only a small part of the universe, and there is no broader context.

The philosophers of science have a desire to apply such a philosophical method to the natural sciences, and especially to cosmology. The fact is that space objects are not as such as they are observed from the Earth, but they represent peculiar phenomena of consciousness. The "transcendental shift" changed the interest from empirical research to transcendental research, which in turn does not diminish the importance of empirical sciences, but complements the understanding of the results of their research. Philosopher Alexei Nesteruk from the University of Portsmouth, England, in his article Towards Constituting the Identity of the Universe: Apophaticism and Transcendental Delimiters in Cosmology, is studying the place of realism in modern cosmology. He wrote that the limits of understanding of the Universe are arising from the specifics of the human condition. From this idea follows the conclusion about the need to abandon the strict truths of cosmological definitions. This entails the need to weaken the requirement of strict realism in cosmology: "Correspondingly, cosmology models the universe as a whole (that is as a global extended space and time) by using observations and physical theories developed in its infinitesimal part, that is on the planet Earth, and within a tiny period of time with respect not only to the age of the universe, but to the history of humanity as well" [Nesteruk, 2012: 381]. Agreeing with this thesis should add the following ideas. Since all of our knowledge of the cosmos is drawn from observations made on the same planet, this situation is reminiscent of Hegel's critical analysis of abstract thinking. The space we are observing is not such at the moment; moreover, it is not represented as such as it was in the past. He appears to us as such only because we observe him from such time and space, and that is not homogeneous. "Thus the transcendental 
constitution of the universe naturally requires the extension of the cosmological quest to the intelligible realm thus extending the very body of the physical cosmology beyond the physical as such. The physical itself becomes a matter of constitution appealing to some general rules of the understanding and reason that is to the principle of human rationality" [Nesteruk, 2012: 382].

Scientists believe that space and time, as everything in them, are objects of perception. In fact, they are not objects of perception, for the same reason that the eye cannot see itself. The eye can see the reflection of itself in the mirror, but not itself. We see all things in space and perceive all things in time, but we cannot see space itself and sense of time. Therefore, a philosophical question arises before a scientist: how to study the cosmos and not the objects of the cosmos? Every perception presupposes the concepts of space and time, according to the transcendental philosophy, if we did not have a priori concepts, then sensory perception would not be possible at all.

Empirical philosophy has studied human perception in detail, but its principles are not applicable to space objects and to space. The fact is that the perceived reality on the earth seems momentary; the objects perceived not far away are at the same time as the objects on the horizon. Since the time of Augustine of Hippo (354-430), there has been an idea of subjective perception of time; he believed that there are three times. In Book XI of the Confessions (397), Augustine explored the nature of time. He made the following claims regarding the past, present, and future: "The past is no longer, it was; the future is not yet, but it will be; the present is, but cannot last because if the present would last, then it would be eternity and not the present" [Augustine, 2006: 242-243]. With what time does a scientist work when he looks at the starry sky? Being in his subjective time, the astronomer is sure that he is looking at the sky and seeing the past of the cosmos. This is due, as has been said, to the speed of light. Light takes years, centuries, thousands of years and more to fly from distant stars to an observer on Earth. However, the problem is that the astronomer does not look into the past, in his earthly understanding. Applying the concept of the past from earthly experience, we forget that the cosmos is not a homogeneous past. In the perception of the starry sky, different stars are in different past, close stars look like they were decades ago, distant stars look like they were thousands of years ago. All this is perceived by an astronomer as a flat image, as a collage of different periods of the past. Since all objects of space are perceived from different periods of time, we can only talk about a specific phenomenon of the observed space. And this phenomenon has never had a real connotation, the cosmologist will never be able to see the cosmos in its present state, but also the astronomer will never see the cosmos as it was at one moment in the past. Our consciousness accepts light and forms phenomena, in the same way, we experience the world, but we see only visible light. A person sees only one percent of the light spectrum and he is convinced that the world looks exactly as it seems. In modern cosmology, scientists use more objective characteristics of space objects. For example, the red color of the planet Mars, known since ancient times, is specified in science by natural light. Studying space, scientists have long used ultraviolet waves, radio waves, X-rays, which expands our knowledge of space, but creates new transcendental phenomena. Thus, the transcendental methodology in physical cosmology brings a new conception of the cosmos.

The modern philosophy of cosmology is closely connected with physics and mathematics, it studies the paradoxes faced by science. For example, there is the paradox of the origin of inertia known as the Mach Principle. The idea that inertia is due to distant matter belongs to Julian B. Barbour and Herbert Pfister. Alternatively, for example, there are various attempts to solve the time arrow Paradox. If symmetry predominantly occurs in physics, 
then where does the arrow of time come from? There are different views on this problem, for example, the theory of Georg F. R. Ellis, or another look of Roger Penrose. For philosophers, the presence of a large number of theories, pluralism of opinions in physical cosmology suggests that there can be no consensus. For them, there is no sufficient evidence in favor of a particular theory, and the world of nature extends far beyond what can be directly established through observations or experiments. At the beginning of the $20^{\text {th }}$ century, French physicist, philosopher, and historian of science Pierre Maurice Marie Duhem (1861-1916) declared about the difficulty in establishing physical theories conclusively. Pierre Duhem analyzed from a philosophical point of view two directions in science: the explanatory theory of Descartes-Laplace on the one hand, and the descriptive theory of Pascal-Ampere on the other. The first theory should explain the scientific discoveries, the second - to systematize the results. However, Pierre Duhem considered that in his logical system the physical theory is not an explanation of the experimental data, as there are always facts that are inaccessible to the researcher. Based on the limited facts of boundless phenomena, such an interpretation belongs to the field of metaphysics. Developing, science will move away from this method, accumulating and systematizing the theoretical experience of experimental results. Pierre Duhem outlined his philosophical views on the problem of science in his book The Aim and Structure of the Physical Theory, 1906 [Duhem, 1954]. In the second half of the $20^{\text {th }}$ century, another philosopher Willard Van Orman Quine (1908-2000) offered the argument for a strikingly general version of underdetermination. Together, these two points of view are called the Duhem-Quine thesis, which states that it is impossible to definitively determine the truth of a scientific theory, but it is possible from a philosophical point of view to evaluate. If Pierre Duhem claimed that it is impossible to test one hypothesis separately from others, and thus find out which is correct and which is not, and then his colleague Willard Quine argued that in spite of everything, any knowledge can be considered as true if we make adjustments in some other fragment of the knowledge system. From the Quine's thesis follows the unfalsifiability of scientific theories, as well as the possibility of their endless edits based on new facts. These views are close to the ideas of conventionalists, who believe that the essence of all theories is the agreement of scientists. The ideas of Willard Quine are criticized by philosophers of science, for example, Larry Laudan. The philosopher criticized the tradition of positivism, realism, and relativism; thereby he defended science as a progressive and privileged institution against social problems.

\section{Anglo-American and Ukrainian philosophy and problems of philosophical cosmology}

Thus, not only in physics but also in cosmology, there can and should remain unresolved questions in connection with the large scale of the cosmos. On the one hand, a huge range of problems seems impossible, but there are limits. One of such limits, in the opinion of both domestic and foreign scientists, is the speed of light. There is a visual horizon representing the most distant matter from which we can receive information through electromagnetic radiation. This once again confirms the impossibility of an exhaustive knowledge of space. In an accelerating universe, there are events that will never be visible on Earth, since the signals from future events will be redshifted. There is a limit to the farthest distance that we can see, measuring in units of distance today.

In modern science, there is a curious principle called the anthropic principle. This argument can be formulated as follows: "We see the Universe like this because only in such a Universe could an observer appear". This confirms the subjective principle of perception. 
This principle was proposed to explain from a scientific point of view why in the observable Universe there are relations between the fundamental physical parameters necessary for the existence of life, namely, intelligent life. The physical conditions necessary for our existence influence what we observe. This seemingly paradoxical conclusion is connected with the name of the scientist Robert Henry Dicke (1916-1997). Paul Adrien Maurice Dirac (19021984) noted that the gravitational constant $G$ is approximately equal to the inverse age of the Universe, and suggested that such a correspondence is not accidental, that it is fundamental for all stages of the Universe's development. Robert Dicke showed that the constant $G$ determines the lifetime of stars such as the sun. These stars create chemical elements for the development of life, and also provide energy for life in the form of light and heat. However, in other eras, according to the idea of Paul Dirac, intelligent life simply cannot exist. This was the first modern application of what is now called the weak anthropic principle. However, as historians of science discovered, the idea of the anthropic principle existed for a long time. If the term "anthropic principle" was first proposed in 1973 by the English physicist Brandon Carter, then the first was clearly formulated by the Soviet physicist from Ukraine Abraham Zelmanov (1913-1987) in 1955. Later, he simplified it to the wording "... we are witnessing processes of a certain type because processes of a different type proceed without witnesses" [Zelmanov, 1970: 395-400].

In 1986, the first book was published by John David Barrow and Frank J. Tipler The Anthropic Cosmological Principle, 1986, in which the authors described their philosophical views on cosmological problems. Thus began the growth of the popularity of the theory, and soon the first conferences devoted to this theory took place. Nobel laureate Steven Weinberg stated that the anthropic principle has a somewhat dubious status in physics. And in the opinion of a native of Lviv, Ukraine, Gennady Gorelik, the anthropic principle essentially belongs not so far to physics, but to metaphysics [Gorelik, 1989: 384]. The theory of the anthropic principle once again confirms the need for a philosophical understanding of physical cosmology. The idea that the Universe has such a view as it can be seen by an observer is called the Weak Anthropic Principle. This principle confirms the fact that our view of the cosmos is due to our existence. This can be explained with the following example: If we imagine the time of the existence of space in one earth year, then the observer was born and lives in the summer and tries to understand what spring, autumn, and winter are. The idea of a strong anthropic principle implies the need for the existence of such conditions in the Universe under which intelligent life is necessary. An interesting formulation of the principle was made by the American theoretical physicist John Archibald Wheeler (19112008), who said: "Observers are necessary to bring the Universe into being" [Wheeler, 1927: 27]. Interestingly, this formulation recalls some ideas of the philosopher of the German transcendental idealism Georg Wilhelm Friedrich Hegel (1770-1831). According to Georg Hegel, what is reasonable is real; that which is real is reasonable. He was not an evolutionist, but he believed that the Universe had passed through the stages of development. The central concept of the philosophy of Georg Hegel — the absolute spirit — passes through stages in the process of self-knowledge. So pure logic becomes unreasonable nature and consciousness appears in this nature. Human consciousness is called to know the Absolute, which exists in a way that can be understood. Moreover, the predecessor of Georg Hegel, the transcendental philosopher Immanuel Kant, before studying the Critique of Pure Reason, studied astronomy and even developed a cosmological theory of the development of the Universe from a dust cloud. As Hume emphasized, however, intuitive assessments from everyday life of whether a given event is likely, or requires a further explanation, do not extend to cosmology [Smeenk, 
2017]. The anthropic principle is in apparent contradiction with the cosmological principle of Copernicus, whose discovery was admired by Immanuel Kant. Immanuel Kant called his transcendental discovery the "Copernican Turn". In turn, Copernicus believed that the place where humanity exists is not privileged. Our planet is ordinary in space. If we consider not one planet, but the entire Universe, then the relations between the fundamental constants, which make possible the existence of highly organized matter, are necessary for the emergence of intelligent life. Consequently, only some universes are habitable. In the usual physical space, the Solar System also occupies a rather special position — its orbit in the Galaxy is on the corotation circle, where the period of the star orbits around the center of the Galaxy coincides with the period of the spiral arms. Thus, the Sun rarely passes through the arms of the Galaxy, where near-term outbreaks of supernovae are likely. Such comfortable conditions for the observer cannot lead to the question of destination. Alternatively, that Cosmos influences the observer or the observer on Cosmos?

Take for example the observer effect, which in many respects resembles the ideas of transcendental philosophy. This is a group of hypotheses about the possibility of an observer influencing elementary particles. The physicist Niels Henrik David Bohr (1885-1962) believed that the observer played a leading role in shaping reality. According to Niels Bohr, if without an observer external reality is only a probability, then concrete reality appears only in the process of observation. It is known that some scientists and philosophers consider the concepts of "observer", "man", and "human consciousness" synonymous. The aforementioned John Wheeler suggests the notion of "participant". The aforementioned anthropic principle of John Wheeler means that the Universe without a reasonable participant will not acquire the status of reality. The idea that the observer could determine or change reality did not appeal to Albert Einstein (1879-1955), he joked that then any mouse could change the Universe only by looking at it. However, in quantum physics, the observer played an important role from the very beginning. Therefore, in the end, as the scientists ironically note, Schrödinger's cat ate Einstein's mouse. In this case, it was about the philosophy of physics, which is close to philosophical cosmology. This is a branch of philosophy that studies the concepts and methodology of physics as part of science. It analyzes, for example, the problem of the mismatch of ontological and physical problems, such as understanding the physics and philosophy of the concepts of time and space. The philosophy of physics also includes the problem of causality, which manifests itself only in the physical world and in connection with the latter, the problem of correlation.

Interdisciplinary research always faces the problem of demarcation - the search for the criterion for determining the scientific theory of empirical science and unscientific theory, as well as assumptions and statements of philosophy, metaphysics, and the formal sciences. The task for the scientist is to define the boundaries of science, separating it from other methods of knowledge. As a result of a long dialogue between philosophers of science and scientists in various fields of science, despite some agreement on the fundamentals of scientific methodology, modern philosophers and historians of science rejected the idea of differentiation as a pseudo-problem. In fact, it is very difficult to say where the border of science is. At present, in the philosophy of science, there is much more agreement on particular criteria than on the general criterion of demarcation between science and nonscience. In the preface to the book by Anna-Teresa Tymieniecka (1923-2014), a famous American philosopher from Poland, entitled "Phenomenology and the Human Positioning in the Cosmos: The Life-world, Nature, Earth: Book One", there is the conclusion about the philosophy of the author; "...transcendental realm of logos is not to be identified only 
with human consciousness but also with the entire manifestation of the forces of earth and cosmos" [Tymieniecka, 2012: 5]. In her views, the phenomenologist does not agree with the idea of abstaining from the hasty judgment of objective reality. She said that the human soul is able to reflect the universal ordering of the Universe. American scientist of Ukrainian origin, George Gamow (1904-1968) is one of the developers of the Big Bang theory studied the relict radiation of the universe, which testifies to events billions of years ago. Like many other astrophysicists, he studied space objects that existed long ago in the past. George Gamow set himself the task of simply describing cosmological theories in simple terms, attaching them with philosophical arguments on the topic of infinity, probability theory, the emergence of the world [Gamow, 1947]. Consequently, both cosmologists and physicists study the phenomena of the distant past, having assumptions about their current state. This means that in the conditions of work not with objects, but with their phenomena, science can benefit from transcendental philosophy, which has been dealing with this problem for more than two centuries.

In the Ukrainian philosophy of science, there are attempts of interdisciplinary space exploration. Among them it is worth mentioning the theory of "Evolving matter", according to Oleg Bazaluk: "The theory "Evolving matter" gave the possibility of creating the philosophy of the cosmos, which is a new universal philosophical teaching about being. The new teaching united the disparate scientific knowledge of cosmology, biology, and neuroscience through the general philosophical idea "Those Who Transform the Universe" [Bazaluk, 2018: 12]. On the possibility of cooperation of physical cosmology and philosophy claims American professor James R. Johnson. He argues that such concepts as infinity, the multiverse, are more likely to metaphysics than to physics: "Since parallel universes reside forever outside our vision, future experiments and theoretical calculations can provide only circumstantial evidence for their existence. If experiments are not conclusive, then we are in the realm of metaphysics where proposals by philosophers are as valid as theoretical scientific theories" [Johnson, 2018: 15]. Increased interest in philosophical cosmology is observed in the Taras Shevchenko National University of Kyiv, a number of scientific works on the subject of philosophical cosmology were published by professors of the Faculty of Philosophy, and the course "Cosmology in the History of European Philosophy" was introduced [Rudenko, 2018: 136]. Contemporary transcendental philosophy was developed by German philosopher Harald Holz. He liberated transcendental philosophy from the convergence of neo-Kantianism, also he critically discussed the relation between transcendental philosophy, on the one hand, and neo-empiricism, on the other. He replaced focus from the orientation towards substance to an orientation towards relations [Holz, 2006].

\section{Conclusions}

From the above, we can draw the following conclusions. The use of the transcendental methodology in philosophical cosmology can contribute to a change in the conception of the cosmos, the introduction of new terms and concepts. A new look at realism in philosophical cosmology contributes to the development of physical cosmology, the rethinking of its object. The interdisciplinary dialogue of philosophical cosmology with its methods and physical cosmology with its objects, as shown in the article, promotes mutual development. The use of transcendental methodology will make it possible to clarify the use of terms. For example, the question of the actual form of space objects and space as a whole will be removed. Even the simple question of one of the forms of galaxies, namely the spiral, how do we see it complete? If the object of the intentional act is a spiral galaxy turned sideways 
to the observer, then how it looks causes questions. Suppose its nearest edge is thousands of light-years away, then the farthest edge is located 100 thousand light-years further (according to the approximate size of the galaxy). This means that these two stars are not where they are seen from Earth, but the apparent distance between them is also illusory. This illusiveness is clearly inconsistent with the severity of science, but this problem can be removed by the philosophical concept of the phenomenon.

This application of the transcendental methodology in philosophical cosmology can influence the terms of physical cosmology. Therefore, for example, scientists use not just the term "Universe", but also the clarified term "Visible Universe", thus emphasizing the relative nature of the phenomenon. Such an example is the result of a rethinking of realism in the natural sciences. Such clarifications may apply to other terms, for example, not a "space object" will become the subject of research by cosmologists, but the "space phenomenon". Not the fusion of black holes will be observed, but the phenomenon of fusion of black holes.

Based on the above, the transcendental philosophy will allow rethinking not the concept of space, which has been studied well enough, but the concept of time, whose earthly experience does not apply to phenomena located at so remote boundaries. Visible constellations consist of stars that are not on a plane, but at different distances from the earth, respectively, in different segments of the past. Accordingly, the visible constellation does not reflect reality but can be studied as a phenomenon.

There are events that can occur now at the other end of the Universe, which in the conditions of the expanding space will never transmit information to us. The question of their existence cannot be proved, only predicted. Like many metaphysical questions, they can be asked, but cannot be proved. Thus, cosmology faces the metaphysical problem of the existence of the unprovable. All this testifies to the impossibility of pure positive knowledge without a metaphysical element.

Knowledge about the cosmos can be refined by the subjectivity of perception as is done in transcendental philosophy.

\section{[미] References}

Augustine. The Confessions. Indianapolis: Hackett Publishing Company, 2006.

Bazaluk, Oleg, and Larysa Kharchenko. The Philosophy of the Cosmos as the New Universal Philosophical Teaching about Being. Philosophy and Cosmology, Volume 21, 2018: 6-13. https://doi.org/10.29202/phil-cosm/21/1

Duhem, Pierre. The Aim and Structure of Physical Theory / Edited [and translated] by Philip P. Wiener. Princeton University Press, 1954.

Emerson, Ralph W. Nature. Boston: James Munroe and Company, 1836.

Gamow, George. One Two Three ... Infinity. New York: Viking Press, 1947.

Gorelik, Gennady. The Coincidence of Large Numbers in Cosmology of the XX century. Mathematical Thinking. Moscow: Nauka, 1989.

Holz, Harald. Alternative Kosmologie - Eine Metaphysikalische und philosophische ,Erzählung' der Geschichte unseres Universums. Bochum: European University Press, 2006.

Husserl, Edmund. Ideas Pertaining to a Pure Phenomenology and to a Phenomenological Philosophy — First Book: General Introduction to a Pure Phenomenology. The Hague: Nijhoff, 1982.

Johnson, James R. Multiverse Assumptions and Philosophy. Philosophy and Cosmology. Vol. 20, 2018: 8-17. . https://doi.org/10.29202/phil-cosm/20/1 
Kant, Immanuel. The Critique of Pure Reason / Edited [and translated] by Paul Guyer, Allen W. Wood. Cambridge University Press, 1998.

Kaufmann, Walter. Hegel: Texts and Commentary. Garden City, NY: Anchor Books, 1966.

Minakov, Mykhailo. The problem of experience in the philosophy of Kant. Multiverseum: Philosophical almanac: Collection of scientific works. Vol. 52, 2006: 40-52.

Nesteruk, Alexei. Towards Constituting the Identity of the Universe: Apophaticism and Transcendental Delimiters in Cosmology. Journal of Siberian Federal University. Humanities \& Social Sciences. Vol. 5, 2012: 358-394.

Rudenko, Sergii, Yaroslav Sobolievskyi and Vadym Tytarenko. Cosmology in the Philosophical Education of Ukraine: History and Modern Condition. Philosophy and Cosmology. Vol. 20, 2018: 128-138. https://doi.org/10.29202/phil-cosm/20/12

Smeenk, Christopher and Ellis, George. Philosophy of Cosmology. The Stanford Encyclopedia of Philosophy (Winter 2017 Edition), Edward N. Zalta (ed.), URL: <https://plato. stanford.edu/archives/win2017/entries/cosmology/>

Tymieniecka, Anna-Teresa. Phenomenology and the Human Positioning in the Cosmos: The Life-world, Nature, Earth: Book One. Hanover: Springer Science \& Business Media, 2012.

Wheeler, John Archibald. Genesis and Observership. Foundational Problems in the Special Sciences. Dordrecht, 1977.

Zelmanov, Abraham. Some philosophical Aspects of Modern Cosmology and Related Fields of Physics. Dialectics and Modern Natural Science. Moscow: Musl, 1970. 